\title{
UIT DE GESCHIEDENIS VAN ST. EUSTATIUS
}

\author{
DOOR
}

S. KALFF

Vóór dat de Nederlanders op St. Eustatius kwamen was het eiland reeds bezocht door Engelsche en Fransche zeevaarders. Nog eerder door Indianen, ofschoon daarover geene historische zekerheid bestaat. Maar zij vormden de inheemsche bevolking, zoowel van de ,wilde kust” van Guinea als van de eilanden in de Caraïbische Zee, en een oude put, bekend onder den naam van „Indian well” zou aan hen dien naam ontleend hebben.

Het eiland was ook bekend onder den naam van Statia, bij de Franschen onder dien van St. Eustache; op de kaart van Joh. de Laet werd het aangeduid als Stacio en in den tekst zijner beschrijving als St. Estasio. De komst van Engelschen en Franschen viel tusschen de jaren 1625 en 1629, maar zij bleven er niet. Want het eiland (dat volgens sommigen door Columbus op zijn tweede reis in 1493 ontdekt zou zijn) lokte niet tot kolonisatie. Het vertoonde zich onbewoond, onvruchtbaar en verstoken van drinkwater.

Eerst in 1632 vestigden zich hier Zeeuwsche kolonisten die den dorren bodem vruchtbaar maakten en er tabak, suiker en katoen verbouwden. Zij „,prospereerden” er; in 1665 was de bevolking reeds aangegroeid tot 1600 zielen die leefden onder het bestuur van „patroons”. Als eerste kommandeur, in 1639, wordt Pierre Gardyn genoemd. Eenige „voortrekkers” onder de kolonisten vestigden zich op het naburige Saba; beide eilanden stonden tot de Westindische Compagnie in een andere verhouding dan b.v. Curaçao, en werden eerder als een soort van leen beschouwd. De welvaart werd nog het meest door den han- 
del aangebracht, doch zou grooter geweest zijn wanneer die niet belemmerd was geweest door de voortdurende krakeelen tusschen de patroons.

Sedert 1664 zou de geschiedenis van het eiland gedurig van bestuurswisseling gewagen, van eene opeenvolging van krijgsgebeurtenissen, van verovering en ontzet. Tusschen Engelschen, Franschen en Hollanders ging St. Eustatius jaren lang als een speelpenning van de eene in de andere hand over. 't Begon in dat jaar met de verovering door de Engelschen onder Holmes. In 1665 schreef de vice directeur van Curaçao aan bewindhebbers der W.-I. Comp. dat de Engelschen „met vier à vyff hondert man St. Estatius sonder eenigh tegenweer met acort (bij accoord) hadden in possessie becomen maer daernaer het acort niet gehouden en d'inwoonders alle uytgeplondert en soo naackt en berooyt op het eylant St. Marten aen landt gesett en op voorsz. eylant St. Estatius een nieuwen Engelsen gouverneur met Engelse inwoonders van de naest gelegene eylanden in plaats van de Duytse inwoonders daerop gebraght, en voorts geresolveert waaren die andere naer bygelegene eylanden meede in te neemen, en voort laetste dit eylant Curaçao; en genoeghsaem gelyck als met eenen eet geswooren die Hollanders gants ende int geheel uyt dese West Indies te doen ruymen."

Te voren was de vloot van admiraal de Ruyter op komst geweest, en dien hadden de Engelschen niet afgewacht. Hij verscheen ook hier als de kampioen van een kleine maar strijdbare zeemogendheid; van een land dat gelijk de Engelsche geschiedschrijver Macaulay het uitdrukte," gave us a king and many a good trashing." Over deze episode van Bestevaer's zeemansloopbaan schreef zijn biograaf Gerard Brandt:

„Het eiland Sint Eustache, tusschen Sint Christoffel en Saba geleegen wordt ook onder de Karibes of Antilles getelt staande onder 't oppergebied der Heeren Staaten der vereenigde Nederlanden, die den Heer Pieter van Ree en zyne medestanderen, voortreffelyke kooplieden te Vlissingen, den eigendom van dien toestonden, dewijl ze daar een volksplanting van Zeeuwen en Hollanders hadden op- 
gerecht. Op dit eiland vond men alles in rep en roere want de Zeeuwen, die hier 't bewind hadden, de Hollandsche scheepen ziende, meenden dat het Engelsche waaren en dat ze 't op hen gemunt hadden. Men stelde hier terstond ordre om zooveel boonen op te koopen als men kon bekoomen. De Heer de Ruiter voer zelf met eenig gezelschap aan land en bevond dit eiland 't welk maar vijf mijlen in zijnen omring groot was, slecht van vruchten voorzien en zeer droog, want men had daar in vier maanden geen regen gehad. D'opperbevelhebber van 't eiland Pieter Adriaanszoon en zijne Raaden vertoonden te dier tijd aan den Heer de Ruiter en zijnen Krijgsraad, dat ze zich gantsch zonder buskruit bevonden en daagelijks den aanval der Engelschen te verwachten hadden, verzoekende met eenig kruid uit de vloot geholpen te worden. Hierop werd goedgevonden hen 700 pont tegen 50 gulden 't hondert over te doen, om zich tegen d'Engelschen te konnen verweeren. Dit geschiedde op een wisselbrief, bij den Heer Ree te Vlissingen te betaalen. Enz."

De vloot had hier nog een van die orkanen te doorstaan waarvoor de Caraïbische Zee berucht was. Men had gebrek aan leeftocht, en daarin kon een eiland met zoo weinig hulpbronnen niet voorzien. Van daar dat de Ruyter besloot zijn tocht voort te zetten naar Terra Nova (Newfoundland), tevens om daar den vijand op te zoeken. Tevoren liet hij nog een zestal prijsgemaakte Britsche vaartuigen aan den wal van St. Eustatius verkoopen, en het teekende eenigszins de productie van het eiland dat de koopprijs in katoen en suiker betaald werd. Eerst na zijn vertrek kwamen de Engelschen opzetten, en toen waren die 700 pond buskruid niet bij machte om het veege eiland te redden. Evenwel bleef de Brit niet lang in 't bezit van zijn buit, want hij werd op zijn beurt door de Franschen verdreven. En deze hielden het eiland in hun bezit of onder hunne protectie totdat het bij den vrede van Breda in 1667 weder aan Nederland kwam en de verdreven kolonisten terugkeerden.

Vijf jaren slechts duurde dit herstel. Toen in 1672 de Republiek met Frankrijk in oorlog geraakte moest St. 
Eustatius zich aan eene Fransche vloot overgeven, doch werd in 't volgend jaar door de admiralen Binckes en Evertsen heroverd. 't Ontzet duurde niet lang; thans waren 't de Engelschen, die zich van het eiland meester maakten, en ze behielden het totdat het in 1674 bij den vrede van Westminster werd teruggegeven. 't Was eene poovere bezitting (waarvan het eigendomsrecht in 1683 aan de W. I. Comp. was overgegaan) doch het eiland was gunstig voor de scheepvaart gelegen; het bezat in de Oranjebaai een ruime natuurlijke haven en bood uit een strategisch oogpunt een voordeelig soutien in deze wateren. Van daar dat drie zeevarende mogendheden elkaar dit punt betwistten. 't Eerst kwamen nu weer de Franschen opdagen; de kommandeur Schorer moest het hun in 1690 overgeven, doch zij werden spoedig door de Engelschen verdrongen, die er tot 1696 stand hielden. Toen gelastte de regeering van den koning -stadhouder WillemIII om deze ,,begroeide rots" aan Nederland terug te geven. Daarna werden de drie bovenwindsche eilanden onder het beheer der W. I. Comp. gebracht. Doch de onrust der tijden hield er de welvaart tegen; wanneer er al geen openbare oorlog in deze wateren werd gevoerd, dan heerschte er toch de kaapvaart. En die kaapvaart kende geen vaderland, geen bevriende volken; alleen overmacht. De Caraïbische Zee was het wijde pekelveld waar de befaamde flibustiërs hunne strooptochten hielden, de koopvaarders enterden, de kustplaatsen plunderden en de eilanden brandschatten, Engelsche Fransche en Spaansche kapers gingen hier om de winst ,craeybecken”; de toestand op deze verontruste zee zou nog lang blijven gelijk de dichter dien voorstelde in zijn vers op een:

Nomadenstam der zee, dle zich op 't grensloos diep, En niet in 't ruige woud een bloedig.jachtveld schiep En, tuk op bloed en buit, de rijkgeladen schepen, Waarin het siddrend West zijn schatten weg zag slepen Naar Spanjes plonderkust, vervolgde langs het zout, Gelijk des jagers boog den wilden stier in 't woud ${ }^{1}$ ).

Ook de handel van St. Eustatius had van deze kapers, vooral de Engelsche kapers, veel telijden. Volgens lijsten,

1) H. A. Meyer. De Boekanier. 
die in 1758 door Amsterdamsche kooplieden werden opgemaakt, gingen in dat jaar veertien voor dit eiland bestemde schepen verloren, met ladingen die te samen eene waarde van bijna twee millioen gld. vertegenwoordigden.

Doch op het laatst van de 18de eeuw brak er een oorlog uit, welke aan deze bevolking groot voordeel bracht; volgens het spreekwoord: 't is een slechte wind, die niemand iets goeds aanblaast. Gedurende den onafhankelijkheidskrijg, dien de in opstand gekomen koloniën in NoordAmerika tegen het Engelsche moederland voerden, beleefde St. Eustatius een tijd van ongekenden voorspoed, en die nimmer zou terugkeeren. Het eiland werd toen, hoofdzakelijk tengevolge van de gunstige ligging, een rendezvous voor vreemde schepen, een stapel- en transitohaven voor den handel tusschen de jonge Amerikaansche republiek en de zeevarende volken van Europa. Engelsche fabrikaten, langs een omweg herwaarts gevoerd, en Fransch buskruit werden er verruild tegen Amerikaansche tabak en ruwe katoen. De handelswaar werd er grootendeels aangebracht door Hollandsche kooplieden, vaak in commissie voor Fransche huizen. St. Eustatius heette toen ,the magazine for all the nations on the earth". Allerlei goederen, die een land in z'n opkomst noodig had, werden van daar naar Amerikaansche havens gevoerd, niet het minst geschut, wapenen en ammunitie, welke men daar noodig had om den strijd tegen de Britsche „rooineks” vol te houden. Een groot deel van die oorlogsbehoeften werd verscheept te Amsterdam; verscheidene Amsterdamsche regenten waren bij deze met het volkenrecht in strijd zijnden handel betrokken. De voorraad goederen was vaak zoo groot, dat daarmee een dubbele rij van reusachtige pakhuizen werd gevuld, grootendeels opgemetseld met de uitmuntende tras, welke een van de natuurlijke voortbrengselen van het eiland was en waarvoor het in geheel West-Indië bekendheid had. Nog heden ten dage herinneren de bouwvallen dier pakhuizen aan deze voorbijgegane handelsgrootheid. Zelfs konden ze den voorraad niet bergen, de goederen lagen op het strand langs de reede opgestapeld. Het eiland werd door schepen 
van alle volken bezocht, zoodat er dikwijls 6 tot 700 handelsvaartuigen voor anker lagen.

Het eiland zelf produceerde toen ook verscheidene koloniale handelsgoederen. Reeds op eene kaart van het jaar 1740 stonden 80 plantages vermeld, waar ongeveer 5000 negers werkten en waar meest suiker, indigo, tabak, koffie en katoen verbouwd werden. In 1780 werden duizende kilo's van die producten uitgevoerd, zoomede cacao, peper, huiden, schildpad, verfhout en rum. Doch den doorslag gaf de handel, feitelijk de smokkelhandel. In de jaren 1778 en 1779 werd het eiland door meer dan 3000 schepen bezocht. St. Eustatius heette toen in den mond van winstgrage kooplieden ,the Golden Rock”, of ook „the Diamond Rock"' 1).

In Engeland keerde de nationale verontwaardiging zich tegen eene zg. bevriende natie, die aldus een oproerig wingewest ondersteunde. In het Parlement werd gesproken van een zeerooversnest, dat St. Eustatius heette, en waarvan men zich, hetzij 't oorlogs- of vredestijd was, zoo spoedig mogelijk moest meester maken. Het werd gezegd dat de oorlog in Amerika reeds geëindigd zou zijn, wanneer die niet uit dezen haard gevoed werd. Ja, uitte zich een der honorabele sprekers, ,indien St. Eustatius vóór drie jaren in zee ware verzonken. dan hadden wij reeds met George Washington afgerekend!'

De Britsche gezant in Den Haag, Yorke, ontving dan ook van zijne regeering den last om bij de Staten Generaal te protesteeren tegen devoor Engeland zoo nadeelige handelsmouvementen, welke in eene Nederlandsche kolonie hun steunpunt hadden, terwijl de Britsche kruisers ijverig jacht maakten op schepen met contrabande aan boord. Er werden zooveel van deze smokkelvaartuigen op gebracht, dat de assurantiepremie op de Amsterdamsche Beurs destijds van 20 tot 30 pct. steeg. Voor de Britsche zeelieden was dit een voordeelige vaart, want er werd veel

1) Vele bijzonderheden over dezen tijd zijn te vinden in de „Depèches” van Thulemeyer 1763-1788, in de bewerking van Robert Fruin, ingeleid en aangevuld door H. T. Colenbrander, Amsterdam 1912. (Werken uitgegeven door het Historisch Genootschap, gevestigd te Utrecht, derde serie, No. 39). 
prijsgeld verdiend, en zooals Byron in zijn Don Juan het uitdrukte:

Sweet is revenge, especially to women,

Pillage to soldiers, prize-money to seamen

Doch de smokkelhandel verminderde daarom niet. Het werd gezegd dat er, alleen reeds op het buskruit, zooveel verdiend werd (soms meer dan 120 pct.) dat men nog winst kon maken wanneer er van drie schepen twee door de Engelschen werden opgebracht. De Staten Generaal verboden dezen met het volkenrecht strijdigen handel, zonder dat dit verbod iets uitwerkte. De reeders van dien tijd waren 't blijkbaar eens met dien scheepseigenaar uit de dagen van prins Maurits, welke Zijne Hoogheid onbevangen verklaarde dat hij om winst zijne schepen zelfs naar de hel zou zenden. al moest hij er zijne zeilen bij schroeien. Het Britsche protest werkte voorshands slechts zooveel uit, dat de gouverneur Heyligers teruggeroepen werd ${ }^{1}$ ). Heyligers werd vervangen door Joh. de Graeff, en 't was den Engelschen geen geringe ergernis dat deze op 16 Nov. 1776 voor 't eerst een officieel saluut liet brengen aan de Dertien Strepen, de vlag onder welke hunne opgestane koloniën zich vereenigd hadden. Dit saluut gold het Amerikaansche schip Andrea Doria, dat krijgsbehoeften kwam halen voor het leger van Washington. De gezagvoerder, kapt. Robinson, bood den gouverneur een afschrift aan van de Amerikaansche onafhankelijkheidsverklaring, waarbij deze de opmerking maakte dat zijne landgenooten voor dezelfde zaak der vrijheid streden als waarvoor Nederland in 1567 de wapenen had opgevat tegen Spanje. Tevens voor het recht om zich aan onwettige belastingen te onttrekken. Hij gaf toen den last om uit de kanonnen van het fort Oranje het saluut te brengen; een feit, dat door de Amerikaansche pers met erkentelijkheid werd herdacht. Het portret van de Graeff kwam sedert in de vergaderzaal van het Kapitool te Con-

1) Deze was later gehuwd met Catharina Elisabeth Rungé, weduwe van mr. Joan Seba Marcus, die tijdens den inval van admiraal Rodney van het eiland verdreven werd en in 1784 te Amsterdam overleed. Navorscher, 1890 , blz. 14. 
cord (New Hampshire) te hangen. Intusschen werd de gouverneur voor deze zaak ter zijner verantwoording naar Nederland geroepen, en verklaarde toen - „les excuses sont faits pour s'en servir" - dat hij niet bedoeld had de onafhankelijkheid der Vereenigde Staten te erkennen, maar de Andrea Doria slechts als koopvaardijschip gesalueerd had, en dat met twee schoten minder dan het schip zelf gelost had ${ }^{\mathbf{1}}$ ).

De ongekende welvaart op St. Eustatius vóór het jaar 1780 bracht een snellen aanwas van bewoners mee. Het bevolkingscijfer werd toen op 20.000 , zelfs op 25.000 zielen geschat; doch dit cijfer was geenszins authentiek, en in elk geval waren een groot aantal slaven daaronder begrepen. Allerlei nationaliteiten werden toen onder de blanke fortuinzoekers gevonden, o.a. Grieken en Turken. Ook Engelschen waren er tamelijk ruim vertegenwoordigd; goede kooplui, maar slechte patriotten, die niet schroomden hun voordeel te doen contrarie het belang van hun vaderland.

Nauwelijks was in 1780 de oorlog tusschen Engeland en Nederland uitgebroken, of St. Eustatius was het eerste mikpunt. De Britsche autoriteiten op Barbados ontvingen den last terstond een aanslag op het eiland te ondernemen; eene vloot van 16 linieschepen onder bevel van admiraal Sir George Bridges Rodney, en vergezeld van eenige fregatten, bombardeergaljoten en kleinere vaartuigen, zette koers naar het eiland. Den 3 Febr. 1781 kwam men daar voor de reê, en vond geringen tegenstand. Er lag slechts een enkel Nederlandsch oorlogsschip, de Mars, van 36 stukken en bemand met 250 koppen onder bevel van F. S. graaf van Bylandt. Deze was met de oorlogsverklaring nog niet bekend en meende dat de Engelsche schepen zouden voorbijvaren, of dat ze 't gemunt hadden op voor Amerika bestemde smokkelschepen. Men hielp hem spoedig uit den droom met de kennisgave van den staat van oorlog, en den eisch zijn schip over te geven.

1) Zie het artikel van Mr. B. de Gaay Fortman: „Eene bladzijde uit de geschiedenis van St. Eustatius", in De West-Indische Gids,," tweede jaargang (Maart 1921),, blz. 558-572. 
Van Bylandt weigerde, waarop een vuurgevecht volgde. Maar dit duurde niet lang, want de strijd was te ongelijk, en weldra moest de Mars de vlag strijken. Daarmee was ook het pleit beslecht; 150 koopvaarders vielen den Engelschen in handen, en doordien zij de voorzorg namen om de Hollandsche vlag van het fort te laten waaien, werd dit aantal met nog 17 misleide vaartuigen vermeerderd. Alle handelswaar in de pakhuizen en op het strand werd buit verklaard; evenzoo al het gereede geld. De waarde van het verbeurd verklaarde geld en goed bedroeg meer dan 3 millioen. De Amerikaansche kooplui en zeelieden, ten getale van ongeveer 2000, werden als krijgsgevangenen naar Engeland gezonden; de overigen, Franschen, Engelschen, Joden, Nederlanders die Amsterdamsche huizen vertegenwoordigden, moesten het eiland ontruimen. Have en erf werden verwoest en geplunderd; het archief werd door de overwinnaars als privaat gebruikt, waardoor het grootste gedeelte van de bescheiden reddeloos verloren ging. Het geweld aan lijf en goed gepleegd herinnerde aan de verhalen van de strooptochten der oude Noormannen; het werd ook in het Britsche parlement gebrandmerkt door een zoo welsprekenden redenaar als Edmund Burke. In zijn „Aanteekeningen” schreef kapt. van Bylandt:

„Aan land was het naar gesteld; alle de goederen, aan de baay leggende, wierden afgescheept, de pakhuysen waren verzegeld en een ieder moest klagen over de brutaliteit en knevelarijen van den kolonel Cockburne, Quartiermeester-Generaal en hebbende het vertrouwen van den Generaal Vaughan (bevelhebber van het Engelsche krijgsvolk). Dezen Cockburne zijn gedrag was zóó dat ik geen zijner landslieden, zoowel militairen als anderen, nog gesproken heb, die hem niet vervloekten als een schandvlek voor de Natie" ${ }^{1}$ ).

De admiraal Rodney, die overigens gestrenge en bepaalde bevelen had gekregen, werd in de levensberichten geenszins afgeschilderd als een hardvochtig en onmeedoogend bevelhebber, zoodat de schuld voor het op St. Eusta-

1) De Jonge. Gesch. Ned. Zeewezen. V, blz. 521. 
tius gepleegde vandalisme wellicht terugviel op Cockburne, maar hij duldde het althans. De geschiedenis van dezen historischen plundertocht, waarbij de Engelschen in roofzucht en geweldpleging bij de beruchte flibustiërs niet achterstonden, zou o.a beschreven worden in een ten jare 1781 te Amsterdam verschenen geïllustreerd geschrift getiteld Engelsche Tieranny ${ }^{1}$ ). Ook werd daarvan melding gemaakt in een treurdicht onderteekend W. V. O. Caspersz., dat in hetzelfde jaar verscheen onder den titel Traanen van een gryzen Hollander gestort om de naare toestand van zijn land veroorzaakt door de schandelijke overwinning der Engelschen in de West Indiën.

De groote voorraad der buitgemaakte goederen werd gedeeltelijk naar de naburige Engelsche eilanden gezonden, gedeeltelijk naar Engeland, terwijl het overschot in 't openbaar werd verkocht. Vooral de Denen van St. Thomas traden als koopers op, doch van daar vonden die goe, deren toch wel weer hun weg naar Amerika. En de bezending voor Engeland kwam daar nimmer aan, want ze werd onderschept door den Franschen admiraal de la Motte Piquet, die zich bij deze gelegenheid van 23 rijk geladen koopvaarders meester maakte. De roover werd op zijn beurt beroofd.

Aan deze tragedie zat een tweede vast; op den buil zou nog een puist komen. Rodney had bij zijn komst voor St. Eustatius vernomen, dat een paar dagen te voren een Hollandsche retourvloot van daar vertrokken was onder geleide van een oorlogschip, dat eveneens Mars heette, onder bevel van den schout-bij-nacht Willem Crull (of Krul). 't Was een schip van 60 stukken; de kommandant was heer van Burgst, onder Prinsenhage, en had het land reeds 33 jaren gediend. Aanstonds zond de Britsche admiraal drie schepen van zijn vloot af om dit konvooi te achterhalen. 't Waren de Monarch met 78 stukken en 600

1) Gedurende den wereldoorlog 1914 - 1918 werden nadrukken van dit boekje in massa verspreid en als propaganda middel tegen Engeland gebruikt. De teekeningen zijn van C. Brouwer. Zie over dezen herdruk „Het Boek", tweede reeks van het Tijdschrift voor Boek- en Bibliotheekwezen. (Martinus Nijhoff, den Haag), 14e jg, No. 6-7, Juni-Juli 1925, blz. 247249. 
man, de Panther met 60 stukken en 450 man, en een kleiner schip, de Sibille, met 28 stukken en 200 man. Deze vormden derhalve eene aanzienlijke overmacht tegenover de Mars, die ook veel minder geschut aan boord had. Crull was evenmin als v. Bylandt, bekend met het uitbreken van den oorlog. Hij verkeerde in het denkbeeld dat de Engelsche schepen, die hem opzeilden, zijn vaartuig wilden praaien, en had daarom in 't vooruitzicht den Britschen bevelhebber bij zich aan boord te zien, zijn uniform groot tenue aangetrokken. Volgens het verhaal van een zijner officieren wandelde hij, toen de Engelsche schepen in 't zicht kwamen, ongekleed, in witte jas en op pantoffels, op het halfdek. De bewegingen der vreemde schepen duidden er spoedig op, dat er onweêr aan de lucht was. Een daarvan naderde dichtbij, zóó dat men 't den Hollander te verstaan kon geven bij te draaien en de vlag te strijken. Dit werd door Crull geweigerd, en aanstonds ont wikkelde zich het vuurgevecht.

Het was al dadelijk een nadeel voor de Mars, dat de onderste batterij, waar juist de zwaarste stukken stonden, door 't overhellen van het schip onbruikbaar werd. De trompen dompelden zich in zee, men moest tegen het binnendringend water de geschutpoorten sluiten. Daar het gevecht op korten afstand gevoerd werd, had bij den ongelijken strijd de Mars weldra belangrijke schade; er vielen dooden en gewonden. Door zijn uniform deed Crull zich door de Engelsche scherpschutters opmerken; het gevecht had nog geen half uur geduurd of een musketkogel trof hem in den schouder. Evenwel bleef hij op zijn post, en het bevel voeren. Doch niet lang meer, want kort daarop trof een tweede kogel hem in de borst, en ditmaal was het schot doodelijk. Stervend hoorde men hem nog zeggen tegen den Franschen officier der zeesoldaten, die hem opving: „Dites au capitaine qu'il baisse le pavillon!” Blijkbaar wenschte hij het verder bloedvergieten voor een verloren zaak te voorkomen.

Ofschoon het schip toen reeds nagenoeg reddeloos was geschoten, werd na zijn dood door zijn opvolger, kapt. v. Halen, het gevecht nog eenigen tijd doortgezet. Toen deze 
eindelijk de vlag streek, was de Mars zoodanig gehavend dat de Engelschen het schip op sleeptouw moesten nemen. Met dien prijs en met de 23 gekonvoyeerde koopvaarders, waarvan er slechts één ontsnapte, keerde men naar St. Eustatius terug. Daar werd het lijk van den gesneuvelden schout-bij-nacht plechtig ter aarde besteld. Men overdekte de kist met de Prinsenvlag, en legde kruiselings daarover degen en scheede. Alle Engelsche kapiteins sloten zich bij den rouwstoet aan, terwijl van de $M$ ars en van het fort Oranje 60 minuutschoten gelost werden. De kist werd onder militaire eerbewijzen bijgezet in den grafkelder der kommandeurs van het eiland op het Gereformeerde kerkhof. In het vaderland verwekte dit sneuvelen eene deelneming en eene bewondering, die zich uitten in verscheidene eerdichten, o.a. van Bilderdijk. Het wapenfeit werd bezongen door Le Francq van Berkhey in zijn Zeetriumph, en door A. Loosjes in de vijf zangen van zijn vers St. Eustatius genomen en herwonnen. Ter eere van zijne nagedachtenis werd een penning geslagen (afgebeeld en beschreven bij van Loon) die aan de voorzijde zijn borstbeeld vertoonde, aan de keerzijde het zeegevecht waarin hij sneuvelde, met zijn wapenschild en maritieme attributen. Het omschrift luidde: Vi inferior non virtute (zwakker in macht, niet in moed) zoomede: Pugnans occubuit (strydende gesneuveld) 4 Febr. 1781. Het onderschrift van zijn portret door Heinsius doelde nog op de omstandigheid dat Crull, in zijn onwetendheid van den oorlog, zich niet bij tijds tot tegenweer gereed had gemaakt, en meende in de Engelschen eerder vrienden dan vijanden te zullen vinden. Het vers luidde:

\footnotetext{
Hoe duur staat u, o Krull, der Britten trouweloosheid!

Van vreêbreuk onbewust, ziet ge u te wreed misleid, Gij staat gereed om hen te groeten als uw vrinden, En dat vertrouwen stelt $u$ bloot Voor 't mikken van 't gevloekte lood, En doet $\mathrm{u}$ in de plaats van vrinden moorders vinden.
}

Admiraal Rodney had bij zijn vertrek wel eene Engelsche bezetting onder bevel van kolonel Cockburne op het eiland achtergelaten, maar dit verhinderde niet dat het 
nog in 't zelfde jaar weer voor den Brit verloren ging. De gouverneur van Martinique maakte met 400 Franschen zich van dezen steeds betwisten insulairen post weer meester. Deze gouverneur, markies de Bouillé, overrompelde het fort en deed de Engelschen het veld ruimen; doch vond slechts ledige pakhuizen, verwoeste plantages en eene verarmde bevolking. Echter bracht hij nog ettelijke geldsommen, aan de inwoners ontweldigd, uit de Britsche zakken te voorschijn en gaf ze aan de eigenaars terug. Doch voor de kooplieden, die hier den handel gedreven hadden en voor de eilandbewoners waren de verliezen van dien aard geweest, dat de vroegere welvaart niet terugkeerde. St. Eustatius herstelde zich niet meer van den slag; te minder omdat, na de erkenning van de onafhankelijkheid der Vereenigde Staten, de aanleiding tot den clandestienen handel verviel. Na den inval van admiraal Rodney verminderde de bevolking snel; vijf jaren daarna waren er van de 20.000 zielen nog 7600 over, waarvan 4000 slaven. Uit een staathuishoudkundig oogpunt zou het eiland in de rij der Nederlandsche koloniën achteraan komen en als eene verdorde provincie gerekend worden.

Ook Saba en St. Martin, door de Engelschen tegelijk met St. Eustatius geplunderd, waren door de Franschen bezet. Eerst in 1784 bij den vrede van Parijs kwamen de drie eilanden aan de W. I. Compagnie terug, doch toen had de handel zich ook reeds verplaatst naar St. Thomas en St. Bartholomé. En die Compagnie zelve, reeds in 1674 ontbonden, daarna gereconstrueerd, ging in 1791 aan schulden en wanbeheer te gronde; waarop over de Westindische en Afrikaansche bezittingen een nieuw bestuur werd aangesteld onder den naam van Raad van Koloniën.

't Zou intusschen niet voor 't laatst zijn dat de ,speelpenning" St. Eustatius van bezitter verwisselde. In de oorlogen der 17de eeuw was de vesting Rynberg (Rheinberg) zoo dikwijls van de eene hand in de andere overgegaan, dat de ruwe soldatenscherts van Spaansche soudeniers daarvoor den naam van putana della guerra had uitgevonden. Zulk eene putana was St. Eustatius onder de koloniën. In 1801 kwam het nog eens weer in Engelsch be- 
zit, hetgeen ditmaal voor de bewoners was aan te merken als eene verlossing. $\mathrm{Nl}$. als eene verlossing van het juk der Franschen. De Bataafsche Republiek was onder den druk geraakt van de Fransche „bevrijders”, al meer en meer, totdat onder het koningschap van Lodewijk Napoleon Nederland tot een vasalstaat van Frankrijk werd. En deze bondgenooten der Patriotten legden niet alleen het moederland zware schattingen op, maar ook zijne koloniën. Een Fransche gouverneur eischte van de bevolking van St. Eustatius eene maandelijksche bijdrage van 8000 Spaansche daalders $(f 30.000)$ met nog de kosten voor onderhoud voor het garnizoen en de defensiewerken. Die gedwongen storting verarmde de inwoners geheel, zoodat in 1801 de Fransche commissaris Cotten verplicht was met eene contributie van $f 1000$ genoegen te nemen. Meer liet zich niet uit den buidel van $c i$-devant kapitalisten persen. Duizende bewoners verlieten toen het eiland, in weerwil van de zware straffen door de Franschen op deze emigratie gesteld. 't Liet zich voorzien dat, bij het slinkend bevolkingscijfer, ook die poovere bijdrage van $f 1000$ eerlang verdwijnen zou. De bot was hier vergald; op 16 April 1801 werd het eiland door de Franschen ontruimd, en daarop door de Engelschen in bezit genomen. Het telde toen nog 2500 inwoners, waarvan eene belangrijke percentage op rekening van het slaven-element kwam. En uit een economisch oogpunt kon men St. Eustatius bij een afgekloven been vergelijken.

Het gezag der Britten, die hier voorwaar en pays de connaissance kwamen, duurde slechts een jaar. In 1802 werd de vrede van Amiens gesloten, waardoor het eiland aan Nederland werd teruggegeven; doch doordien de Republiek door Napoleon in den oorlog tegen Engeland werd meegesleept kon dit land, op 21 Febr. 1810, er zich op nieuw van meester maken. Deze herhaalde perioden van Engelsche heerschappij droegen er gewis veel toe bij dat het Engelsch de taal des lands werd. Voor de bevolking, die zich in Oranjestad (Boven- en Benedendorp) samentrok, geschiedde de rechtspraak volgens de Hollandsche wet, maar die wet was in het Engelsch vertaald, zoodat men 't 
gebeuren zag dat Nederlandsche onderdanen in eene Nederlandsche kolonie een tolk moesten meebrengen. Op de scholen gaven gouvernements-onderwijzers hun onderricht in 't Engelsch, eerst later in 1907, werd daar ook het, Hollandsch gehoord. Het godsdienstonderwijs ging uit van Engelsche zendelingen, tot de kerk der Methodisten behoorende. In 1842 schreef G. v. Lennep Coster dat, indien van het kommandeurshuis niet de Hollandsche vlag woei en de Hollandsche wet er van kracht was, men zich niet anders zou kunnen voorstellen dan dat St. Eustatius tot de Engelsche koloniën behoorde. Slechts enkele ambtenaren en ingezetenen spraken nog Hollandsch. Een gezaghebber van het eiland, G. J. van Grol, liet zich in eene openbare voordracht aldus uit:

„Dat Engelsch de algemeen gekende taal werd, behoeft niet te verwonderen. De voortdurende aanraking met de „onverdraechelyke natie" als opgedrongen vriend, mededinger of vijand, de vestiging van hare landslieden en van vreemden vóór den gulden tijd, het samenstroomen uit alle oorden van kooplieden in dien tijd, de meer en meer veldwinnende invloed van het Engelsche volk in de WestIndies, de verbinding met de vrijheidlievende Amerikanen, dit alles moest de kennis der Engelsche taal wel tot een eersten eisch maken. Doch dat billijkte toch niet de verwaarloozing der Nederlandsche taal, met name na 1816, in eene Nederlandsche Kolonie!"

In dat jaar 1816, toen ook de koloniën in Oost-Indië door Engeland werden teruggegeven, kwam St. Eustatius weder onder de Hollandsche vlag. En ditmaal (Deo volente) voor de laatste maal. Doch de voorspoed keerde daarmee niet terug, de toestand bleef kwijnend. Door de inkrimping van den handel met Noord-Amerika, door het verdringen van de zeil- door stoomschepen en andere oorzaken geraakte de tusschenhandel in verval, daarna ook de groothandel. De suikercultuur gaf nog aan vele handen arbeid, maar weldra deed de beetwortelsuiker de rietsuiker eene doodelijke concurrentie aan. Door de afschaffing van de slavernij werd de toestand nog zooveel zorgelijker; menige plantage kwam toen braak te liggen. Tot het jaar 
1830 kon nog in de eigen uitgaven voorzien worden; na dien tijd zou het eiland, dat in 1779 aan de Westindische Comp. eene bate van 42 mille opbracht, op de kurk van het subsidie blijven drijven. 